\title{
Review of School Physical Education Performance from the Perspective of Public Finance
}

\author{
Cheng Yang, Ying Xiong*, Junming Zhang \\ Wuhan Business University School of Physical Education, Wuhan, 430056
}

Keywords: Public Finance; School Sports; Performance; Commentary

\begin{abstract}
This article from the knowledge and performance evaluation in physical education, performance evaluation and performance appraisal system construction method analyzes the status quo of school physical performance evaluation, that the existence of previous studies lack school sports performance public finance perspective research, performance evaluation lack of basic theoretical support, lack of depth and scope of the research, research methods and lack of performance relative to a single elementary and high school sports and other issues concerned. Proposed in future research studies school financial guarantee and expenditure structure of the sports public should be strengthened; strengthening research school sports public finance investment performance evaluation system; to strengthen the quantitative research school sports public finance performance, from the empirical point of view and actively explore the different levels of schools public finance system and mechanism sports performance evaluation, to provide the necessary basis for the relevant fiscal policies.
\end{abstract}

\section{Introduction}

Under the influence of Western schools of public choice, after more than 10 years of fiscal reform in our country, the 1998 National Conference on Finance established the goal of building a basic framework for public finance. The concept of "public finance" has won the unanimous endorsement of domestic scholars. The research on domestic public financial security has been expanding and extending around the feature of "publicity" of public finance, strengthening the human factor of public finance, clarifying the nature of public service "serving the livelihood of the people", and enhancing the provision of public service capability, effectively promoted the process of equalization of basic public services. The advanced concept of western public finance performance management has aroused the great attention of domestic scholars. Most of the researches focus on evaluating the effect and impact of the implementation of public finance expenditure from the technical means. Physical education is the focus of public finance in our country. School physical education is an important area of public finance to serve the livelihood of the people. From the perspective of public finance performance, it is an important basis for government to formulate relevant policies. The study of public finance performance in school sports is rarely seen.

\section{The Related Content of School Sports Performance Research}

The Understanding and Definition of School Sports Performance Evaluation. Yang Hailong (2009) that the school sports performance is the school sports organizations within the prescribed time frame, in various ways the implementation of school sports results. It is suggested that the evaluation of PE performance in schools should be in accordance with the "Regulations of School PE", including the objectives and tasks of PE, PE and health courses, extracurricular sports activities, school amateur training and competitions, PE teachers, physical examination and evaluation of students, equipment, organization and management of eight aspects [2]. According to Hong Hui (2009), human resources are the key to the quality of physical education in colleges and universities. The implementation of scientific and effective performance appraisal of physical 
education teachers is the key to the university's performance evaluation of sports. The paper proposes that by introducing a high performance department culture and introducing teacher personal development and school strategy The goal of consistent assessment of the target, do a good job position analysis to improve the scientific evaluation, make full use of the assessment results as a promotion, dismissal, transfer positions, pay bonuses to provide quantitative reference to promote the full development of teachers [3]. Wang Zhengxia (2009) proposed that college PE performance is the guide of sports managers to guide management resources and work together to determine the performance of sports and its system, and the overall performance as a guideline to determine the performance of all levels of staff [4]. What Evergreen (2010) set up a "college sports manager performance appraisal system" for managers of middle school sports in colleges and universities, and builds the performance evaluation of school sports managers by tracking the students' physical exercise and physical fitness changes during and after class. System, the use of evaluation, reward and restraint mechanisms to enhance the level of college sports management [5].

School Sports Performance Evaluation Index and System Research. According to the different aspects of school physical education, Hong Hui (2010) adopted the goal management method to construct the performance appraisal system of physical education teachers in colleges and universities from the three dimensions of teaching, scientific research and sports training. Wen Dongliang (2010) adopted the "Balanced Scorecard Method" to divide the sports work of colleges and universities into the evaluation system of four first-level indicators including students, finance, internal processes, learning and innovation, and 14 second-level indicators and 46 third-level indicators and by the analytic hierarchy process to determine the weight of each index, to build an evaluation system of college PE performance [6]. Zhu Chuanghui (2011) established a performance evaluation system of physical education teaching in colleges and universities based on the analytic hierarchy process (AHP), which is based on the teaching preparation, teaching process control, student learning and teaching management. Hu Yang (2009) also adopted the analytic hierarchy process to build a model for assessing physical education in colleges and universities from the perspectives of manpower, financial resources, material resources and intangible inputs, and evaluated the performance of physical education in colleges and universities through fuzzy comprehensive rating [8]. Tang Jing (2012) built an index system of performance evaluation for PE teachers in five aspects of quality, teaching, scientific research, instructional tasks and social services, and scored by experts to give weight to the index [9].

School Sports Performance Evaluation Methods. Song Jiaping (2012) proposed that a large number of fuzzy phenomena and fuzzy concepts are included in the evaluation of physical education teachers in colleges and universities. The fuzzy mathematics method is helpful to quantify these phenomena and concepts. In the construction of index system, AHP (AHP) and fuzzy comprehensive evaluation method are combined to make the performance evaluation scientific and well operable [10]. He Feng (2010) also based on AHP level analysis method, the college PE teachers performance evaluation index weights were studied [11]. Zhang Huawen (2014) proposed to adopt $\mathrm{O} *$ NET system questionnaire to study the work performance of college PE teachers [12].

\section{The Basic Characteristics of School Sports Performance Research}

The Lack of Public Finance from the Perspective of School Sports Performance Research, Thematic Project Is Not Enough. With the continuous improvement of the public financial system and the establishment of the people's livelihood and financial philosophy, the research on public livelihood protection has drawn the common attention of domestic and foreign scholars. Performance appraisal is an important basis and means for assessing and managing public finance. People's livelihood, the study on the performance of public finance has been widely discussed in many disciplines and fields. The related research on the performance evaluation of public finance in sports has also been conducted in many fields within the discipline. However, the performance of public finance in school sports related research is rare. School physical education as the livelihood of the financial security should deserve academic attention, through the combing of the existing literature found that although the current school sports performance studies involving the people, 
money, material and other aspects of school sports, but the relevant research results mostly focused on the performance management of individuals or organizations in school sports. The analysis and discussion on the performance of school sports mainly from the daily work of PE teachers and the daily management of school sports shows that there is little research on the performance of school $\mathrm{PE}$ in public finance, the most relevant research on the performance of sports public finance is the research on the management of school sports expenses. Most of the related research results appeared in the early 90s of the last century, such as Liu Shougu (1993) and Bao Mingxiao (1993) there are few articles in the core periodical about the management of school sports expenses. In recent years, the National Social Science and General Administration of the project are also rarely related to school sports public finance research project. Financial input is the prerequisite and guarantee for the development of school physical education. It includes teachers, stadiums (stadiums), sports equipment and facilities, as well as sports activities for students. It covers most aspects of physical education in schools, the performance of school sports finance Evaluation and management can provide basic judgments for the development of school physical education from the macroscopic level, and can also rationally allocate school physical education resources on a microscopic level. The current lack of research on the performance of school public physical education cannot but be considered as school physical education a shortcoming in the field of study.

Research Depth and Scope Is Limited and Lack of Attention to the Study of Sports Performance in Primary and Secondary Schools. At present, the insufficiency of the depth and scope of school PE performance is mainly reflected in two aspects. First, most of the research results mention the issue of funding and funding management of PE in schools. However, the depth of research and research methods are far from sufficient in comparison with other researches in sports. Performance evaluation and performance management, evaluation methods are qualitatively based, few quantitative research. Second, there is a lack of emphasis on the study of PE performance in primary and secondary schools. A total of 146 research results are found based on the keywords "PE" and "performance" of colleges and universities, and the keywords "PE in primary and secondary schools" and "performance" are retrieved a total of 30 research results only for "college sports performance" a quarter of the research results. It is not difficult to find that most scholars focus their research mainly on the aspect of higher education. There are relatively few related research results in primary and secondary schools. The "Results of 2014 National Student Physique and Health Survey" released by the State Sports General Administration show that the current decline in our physique and health and the obesity problem are still serious in our country, especially in primary and secondary school age groups, which has been increasing year by year with the investment in school sports. Therefore, in addition to strengthening the funding for primary and secondary school physical education, it is necessary to strengthen the management of the school's physical education expenditures, strengthen the study of public financial performance in primary and secondary school sports performance evaluation, and improve the performance evaluation system of primary and secondary school physical education through the meticulous operation of financial input, we will improve the physical and mental health of our young people and increase the effective supply of state finance.

\section{Prospect of School PE Performance Research from the Perspective of Public Finance}

Strengthen the School Sports Public Expenditure Structure and Security Research. School physical education is an important part of public services and an important part of public finance. In 2012, the General Office of the State Council issued "Several Opinions on Further Strengthening Physical Education in Schools" and proposed "Organizing Physical Education Assessment for Primary and Secondary Schools from 2013 onwards" However, at present there is still a lack of a sound evaluation system for school PE funding. The expenditure on PE in schools mainly depends on a certain percentage of the expenditure on public finance education, but there is no uniform stipulation on the specific proportion for local PEs and schools to make arrangements based on the actual conditions. The absence of standards and the vacancy of evaluation system will inevitably lead to the blindness and waste of capital investment. The study on strengthening the public finance 
guarantee and expenditure structure of school sports will help to clarify the structure, operation mode and existing problems of school sports expenditure, , Structure and efficiency of measuring school PE public finance input effect is conducive to follow-up research more systematic and scientific start. The research on the public finance guarantee and expenditure structure in school sports can be shown in the following aspects: the theoretical research on the public financial security in school sports; the study on the scale of public financial expenditure in school sports; and the research on the distribution of public finance in school sports.

Enhance School Sports Public Finance Performance Evaluation System. In April 2014, the Ministry of Education promulgated the Measures for the Assessment of Physical Education in Primary and Secondary Schools, the Measures for the Annual Report on the Work of School Physical Education, and the measures to improve the quality of physical education in schools. Is to strengthen the primary and secondary schools from the system performance evaluation of the two normative documents in the primary and secondary schools in the evaluation system of physical education, "field equipment and funding" is an important two-level evaluation indicators, "funding" links through public funding is whether according to the regulations for sports expenditures, whether to meet the needs of school sports work to two evaluation, simple "yes" and "non" judgments and cannot fully reflect the actual benefits of school sports funding. The research on the influencing factors, the mechanism and the key links in the performance management model of school PE public finance is conducive to clarifying the relationship between school PE funding and public education funding, the relationship between school PE funding and school physical education and students' physical health, and the school physical education funding objectives and direction of work to improve financial supervision and management level. The research on performance model of $\mathrm{PE}$ in public schools can be shown in the following aspects: the analysis of performance factors of SPF in school sports; the research on the effectiveness of PE allocation in school sports; the research on the benefits of SPF in schools; and the technical benefits of PE in public schools.

Strengthen the School Physical Education Public Expenditure Performance Quantitative Research. The Ministry of Education pointed out in the "Key Work Points of the Ministry of Education in 2016" that the focus of future work should focus on raising the level of education funding and management, increasing the supervision over the use of education funds, and promoting the disclosure of financial information. In order to guarantee the investment of school sports funds, we should first change the attitude of investing purely in school sports and not requiring efficiency. In particular, we should supervise and evaluate the financial input and working efficiency of primary and secondary school sports finances, and change the past school sports performance evaluation qualitative and supplemented by the main quantitative research status quo, with the support of institutional economics and econometrics methods, through the performance evaluation of the school sports finance scale, financial allocation, distribution efficiency and other multi-angle empirical research, and actively explore the system and mechanism of performance appraisal of sports public schools in different levels of schools provide the necessary practical basis for the promulgation of school related financial policies. The research on the performance evaluation of school PE public finance can be shown as follows: the research on the performance evaluation standard of school PE, the allocation efficiency of public sports in school sports, the research on the efficiency of school PE public finance, the technical efficiency of school PE public finance and the school PE public finance Transfer payment performance studies.

\section{References}

[1] Zhang Hong-zhen, zhang Rui-lin, Liang Shu. Difficulties and Countermeasures of Youth Sports in China [J] .Journal of Physical Education, 2015 (3): 65-68.

[2] Yang Hailong. Review of China's primary and secondary schools sports performance since the reform and opening up [J]. Shanxi Normal University, 2009, (4): 101-104. 
[3] Hong Hui. Reflections on the performance evaluation of college PE teachers[J]. Acta Metallurgica Sinica, 2009, (3): 108-110.

[4] WANG Zheng-xia.Analysis on Performance Evaluation of Physical Education in Colleges and Universities [J]. P. Culture, 2009, (9): 83-86.

[5] MING Chang-qing, QU Yixia. Study on the Operation of College Sports Management Based on the Performance Appraisal System [J]. Adult Education, 2010, (4): 66-67.

[6] Hong Hui, He Qiuhua. Construction of the performance evaluation index system for physical education teachers in ordinary colleges and universities [J] .Journal of Physical Education, 2010, (8): 82-84.

[7] ZHU Chuan-hui. College Physical Education Performance Evaluation Index System[D]. China University of Petroleum, 2011

[8] Hu Yang, Yin Shaofeng, Zhang Wei. Construction and application of performance evaluation index system of physical education in colleges and universities [J]. Journal of Physical Education Institute of Shanxi Normal University, 2009 (3): 84-86.

[9] JT.Construction of index system of performance evaluation of PE teachers in colleges and universities [J]. Shandong Sport Science and Technology, 2012, (1): 71-74.

[10] Song Jiaping, Du Xiangju. Application of Fuzzy Mathematics in the Evaluation System of PE Teachers Performance in Colleges and Universities [J]. Journal of Beijing Sport University, 2012, (2): 96-101, 107.

[11] He Feng. Study on the Weight of Performance Evaluation Indexes of PE Teachers Based on Analytic Hierarchy Process [J] .Journal of Anhui Sports Science, 2010, (1): 86-88.

[12] Zhang Wenhua. Study on the Performance of College Physical Education Teachers Based on O * NET Work Analysis System [J]. Acta Metallurgica Sinica, 2014,34 (4): 125-128

[13] Hu Jiaqiao. Discussion on Sports Funds Management in Colleges and Universities[J]. Liaoning Higher Education Research, 1989, (2): 102-105.

[14] Bao Mingxiao.On the Influence of Sports Funds on Middle School Physical Education in Anhui Province [J] .Journal of Physical Education, 1993, (4): 20-21, 94.

[15] Liu Shouguo, Xie Guoqing, Wang Ping, Li Hengshan.The Economic Benefit and Evaluation of Sports Investment in Colleges and Universities [J] .Journal of Shanghai Institute of Physical Education, 1993, (4): 18-22.

[16] Xu Tong tolerance. On the management of college sports funding thinking Xu Tong Ren[J]. Shanghai Institute of Physical Education, 1995, (S3): 42-43.

[17] Zhang Jinbiao, Jiang Tongren, Qian Jie. Research on Funding for Physical Education in Colleges and Universities [J].Journal of Beijing Sport University, 2004, (12): 87-89.

[18] WU Jian.Study on the Guarantee Mechanism of School Sports Development Funds[J]. Journal of Henan Institute of Education (Natural Science), 2011, (2): 75-78. 